\title{
Examination of the Relationship Between Exercise Barriers and Physical Activity, Sleep, and Fatigue in Older Individuals
}

\author{
Meral Sertel' (1), Ayșe Abit Kocaman' (1), Sabiha Bezgin' ${ }^{(0)}$, Tezel Yıldııım Șahan² (1), Saniye Aydoğan Arslan' (1),

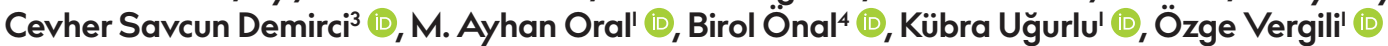 \\ 'Department of Physiotherapy and Rehabilitation, Kırıkkale University Faculty of Health Sciences, Kırıkkale, Turkey \\ ${ }^{2}$ Department of Physiotherapy and Rehabilitation, University of Health Science Turkey, Gülhane Health Science Faculty, Ankara, Turkey \\ ${ }^{3}$ Department of Physiotherapy and Rehabilitation, Balıkesir University Faculty of Health Sciences, Balıkesir, Turkey \\ ${ }^{4}$ Department of Physiotherapy and Rehabilitation, Hacettepe University Faculty of Physiotherapy and Rehabilitation, Ankara, Turkey
}

ORCID iDs of the authors: M.S. 0000-0002-7575-9762; A.A.K 0000-0002-6694-3015; S.B. 0000-0002-8459-8956; T.Y.S. 0000-00024004-37I3; S.A.A. 0000-000I-5470-9849; C.S.D. 0000-0002-8786-7496;M.A.0. 0000-000I-8618-98I7; B.0̈. 0000-0002-3540-7I56; K.U. 0000-000I-58I9-9380; Ö.V. 0000-0002-5312-7684.

Cite this article as: Sertel M, Abit Kocaman A, Bezgin S, Șahan TY, Aydoğan Arslan S, Demirci CS, et al. Examination of the Relationship Between Exercise Barriers and Physical Activity, Sleep, and Fatigue in Older Individuals. Cyprus J Med Sci 2020; 5(3): 226-33.

\section{BACKGROUND/AIMS}

This study aimed to determine exercise barriers in older individuals and to examine their relationship with physical activity, sleep, and fatigue.

\section{MATERIAL and METHODS}

A total of 100 older individuals aged more than 65 years who were staying in a private nursing home and elderly care center were involved in this study. The sociodemographic information of the individuals and the used scales were recorded through face-to-face interviews held by a physiotherapist. Their exercise barriers, physical activity levels, sleep conditions, and fatigue were evaluated by the Exercise Benefits/Barriers Scale, Physical Activity Scale for the Elderly (PASE), Pittsburgh Sleep Quality Index (PSQI), and Fatigue Severity Scale.

\section{RESULTS}

The mean age of older individuals was $71.32 \pm 6.33$ years. There were significant positive and low relationships between exercise barriers in older individuals and the PSQI's sleep quality and day dysfunction owing to sleepiness (DAYDYS) subparameters, the PSQI total score and fatigue. Furthermore, significant negative and low relationships were found between the PASE $($ Leisure activity) and sleep duration, sleep

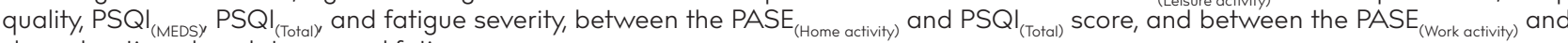
sleep duration, sleep latency, and fatigue.

\section{CONCLUSION}

The study results suggest that conditions such as sleep quality and fatigue can be considered an exercise barrier. Regular exercise training planned for older individuals individually or as a group will improve sleep quality and provide improvement in their fatigue level. It is crucial to plan and implement in particular personal exercise and physical activity programs and lifestyle modifications, physiotherapy rehabilitation, and energy conservation techniques for sleep quality to maintain and improve the health of older individuals.

Keywords: Older, exercise barriers, physical activity, sleep, fatigue

\section{INTRODUCTION}

In the general population, persons older than 65 years experience fatigue significantly more than their younger counterparts (I). Fatigue, specifically in the elderly population, has been associated with many chronic diseases (2). Fatigue is a common symptom associated with these chronic diseases. Several factors, such as pain, sleep deprivation, and the stress of illness or surgery, could contribute to fatigue experienced by elderly persons. Pain may contribute to fatigue by increasing heart rate, blood pressure, respiratory rate, muscle tone, and oxygen consumption. Sleep deprivation results in limited non-rapid eye movement phase during sleep, decline in protein synthesis, and a slower rate of healing (3). In all age groups, insufficient oxygen transport to the muscles mainly caused by anemia, insufficient pumping of blood to 
the muscles caused especially by antineoplastic and cardiotoxic drugs (4), and severe muscle mass atrophy from the catabolic effects of sedentary habits and long-term bed rest (5) can contribute to fatigue.

Nowadays, living by increasing the quality of life has become an issue that is as important as living long. Physical activity is one of the main factors to get older healthily and to minimize age-related health risks using various methods (6). The health benefits of physical activity are well known. Physical activity is effective individually in preventing chronic diseases and socially in improving public health, and it provides physical, social, mental, and spiritual benefits to women and men of all ages (7). Regular physical activity prevents the development of cardiovascular diseases, heart diseases, certain types of cancer, and all causes of mortality. Furthermore, regular physical activity has positive effects on blood pressure, lipid and lipid-protein profile, weight control, mental health, and psychological well-being (8). Regular physical activity supports the quality of life by strengthening the psychological well-being and physical functionality (9). Even moderate physical activity performed 3-4 times a week for 3060 minutes is usually sufficient to reveal its positive effects on our health $(10,11)$.

Although the benefits of regular participation in physical activity are known, recent studies have revealed that participation in a physical activity is generally less than the recommended level (12). Moreover, poor physical fitness results from muscle weakness, decreased muscle mass, gait problems, fatigue, and impaired balance. It is necessary to develop the ability to perform daily life activities to improve the quality of life in geriatric cases. Likewise, performing daily physical activities requires a certain level of physical fitness (13). Physical fitness becomes increasingly important for older individuals because the decrease in physical activity is also a risk factor for falls (14). In particular, physical activity and physical fitness levels decrease with aging $(15,16)$. The physical activity levels of older adults are too low worldwide, with most studies reporting that between $40 \%$ and $80 \%$ of older people do not meet the physical activity guidelines $(17,18)$. In Turkey, physical inactivity rate in older adults is $33 \%$ (19). The results of scientific studies conducted to evaluate the physical activity habits in different segments of society indicate that physical activity has not yet become a lifestyle among older individuals in Turkey. This is thought to be caused by numerous perceived or actual exercise barriers (20). General barriers for all older individuals include physical exertion, expense, embarrassment, and lack of time, motivation, and facilities. In addition,

\section{Main Points:}

- Poor quality sleep is an exercise barrier in older individuals.

- Fatigue is an exercise barrier in older individuals.

- Personalized exercise and physical activity programs should be planned for the maintenance and improvement of health in older individuals.

- Lifestyle modifications and physiotherapy rehabilitation programs are very important to improve sleep quality.

- It is very important to plan and apply energy conservation techniques to prevent fatigue. cohort effects may be seen in older individuals who were raised to avoid vigorous exercise and choose exercises considered 'proper for girls or boys' (2I). Barriers are significantly more important in influencing exercise patterns than perceived benefits (22). Therefore, the society should be inspirer and encouraging for older individuals to be more dynamic and active and to acquire regular exercise habits (23). Because it is never too late to start exercising and benefit from the many advantages that it provides (24), further research into the management and improvement of perceived barriers to exercise is needed. Therefore, this study aimed to determine exercise barriers in older individuals and to examine their relationship with physical activity, sleep, and fatigue.

\section{MATERIAL and METHODS}

Individuals aged more than 65 years who were staying in a private nursing home and elderly care center and volunteered to participate in the study were included. Based on the formula that is used for calculating the sample size of the unknown population, the minimum sample number was determined to be 90 older individuals by accepting a $95 \%$ confidence level and taking the margin of error as 0.I. Older individuals in the institution who met the inclusion criteria were included in the study. Healthy older individuals aged 65 years or older and who agreed to participate in the study, did not use a walking aid, were independent in mobilization, and did not have cooperation and communication problems (individuals with the mini-mental test score of $>24$ ) were included in the study. Patients who had cardiac diseases (angina pectoris, acute myocarditis, a history of myocardial infarction in the last 3 months, aortic aneurysm), pulmonary embolism and deep vein thrombosis in the last 3 months, a history of cerebral aneurysm or intracranial hemorrhage, acute retinal hemorrhage or past ophthalmic surgery, active infection, malignancy, multiple organ failure, terminal disease status, a history of fractures in the lower and upper extremities in the last 3 months, severe hearing and visual loss, Alzheimer's disease, Parkinson's disease, dementia diagnosis, and benign paroxysmal positional vertigo diagnosis were excluded from the study.

Ethics committee approval was received for this study from the ethics committee of Kırıkkale University, Non-interventional Research Ethics Committee, was found to be appropriate in terms of medical ethics (Meeting date: 06.02.2019; decision no: 2019.02.06).

A total of 100 older individuals were evaluated using the faceto-face interview method. First, parameters such as age, gender, marital status, nutritional characteristics, habits, smoking and alcohol use, used assistive devices, personal background information, family history information, educational status, social security, previous or current occupation, vision problems, sleep problem, frequency of falls, causes of falls, and the presence of chronic diseases were obtained. Their exercise barriers, physical activity levels, sleep conditions, and fatigue were evaluated by the Exercise Benefits/Barriers Scale, Physical Activity Scale for the Elderly (PASE), Pittsburgh Sleep Quality Index (PSQI), and Fatigue Severity Scale, respectively.

The Exercise Benefits/Barriers Scale: Ortabağ et al. performed the validity and reliability study of the scale in Turkish (25). The Exercise Benefits/Barriers Scale was developed by Sechrist, Walker, and Pender to determine the perceptions of individu- 
als who would participate in the exercise of the exercise benefits and barriers (Cronbach's alpha coefficient, 0.87). The scale consists of 43 items. The scale has 4 answers ranging from 4 (strongly agree) to I (strongly disagree) in a conditional choice Likert scale format. The scale items 4, 6, 9, 12, 14, 16, 19, 21, 24, 28, 33, 37,40 , and 42 are scored inversely. The total score of the scale ranges from 43 to 172 . The scale has 2 subgroups: the Exercise Barrier Scale and the Exercise Benefit Scale. Each subgroup can be used alone independently. The score range of the benefit scale is between 29 and 116 , and the score range of the barrier scale is between 14 and 56 . The sum of the scores of all items in the scale gives the total score of the Exercise Benefits/Barriers Scale. The higher the total scale score is, the more the individual has understood the benefits of the exercise (26).

The Physical Activity Scale for the Elderly: Ayvat et al. performed the validity and reliability study of the scale in Turkish (27) The PASE is short and easy to use. Validity and reliability studies have been performed for this scale, and in the literature, it is frequently used in the older population. The questionnaire assesses the physical activity of older individuals over the past week and includes the components of leisure, housework, and work-related physical activity. Participation in leisure time activities, such as walking activity outside the house, mild, moderate, and severe sports and recreational activities, and muscle strengthening exercises, is recorded as never, rarely (I-2 days/ week), sometimes (3-4 days/week), and often (5-7 days/week), and the duration of activities is classified as $<1$ hour, $\mid-2$ hours, $2-4$ hours, and $>4$ hours. Cronbach's alpha coefficient was 0.714 for the initial evaluation (27).

The Pittsburgh Sleep Quality Index: Buysse et al. (28) developed the PSQI, which is used to assess sleep disturbances in individuals, and Ağargün et al. (29) conducted the validity and reliability study of the scale in Turkish. The PSQI is a 19-item self-report scale that assesses sleep quality and disturbances over the past month. Each item of the test is scored equally between 0 and 3 . The scale consists of 7 subscales that assess subjective sleep quality, sleep latency, sleep duration, habitual sleep activity, sleep disorders, sleep medication use, and loss of daytime functionality. The scores of the subscales are summed up to obtain the total PSQI score, which ranges between 0 and 2l. A total PSQI score of $>5$ indicates an insufficient sleep quality of an individual, with a sensitivity of $89.6 \%$ and specificity of $86.5 \%$, and a severe disorder in at least 2 of the areas mentioned earlier or a moderate disorder in at least 3 of them (Cronbach's alpha coefficient, 0.80 ).

The Fatigue Severity Scale: The FSS was used to measure the individuals' fatigue. The validity and reliability of this scale have been proven (30). It is indicated as the best example of one-dimensional scales. The person specifies how much he or she agrees with each item by choosing among the numbers from I to $7 ;$ I indicates that he or she strongly disagrees, and 7 indicates that he or she strongly agrees. The score of the scale, which consists of 9 questions, ranges between 9 and 63. A score of 36 or higher indicates severe fatigue (intraclass correlation coefficient, 0.90; Cronbach's alpha coefficient, 0.9I) (3I).

\section{Statistical Analysis}

SPSS version 15 software was used for statistical analyses (SPSS Inc.; Chicago, IL, USA). Descriptive statistics was used to analyze the sociodemographic characteristics of the individuals. The data distribution normality was evaluated using the Shapiro-Wilk test. The variables obtained from the measurements were expressed as percentage (\%) and arithmetic mean \pm standard deviation $(X \pm S D)$. Correlations were examined by Pearson's correlation analysis (<0.3 (poor), 0.3-0.5 (fair), $0.6-$ 0.8 (moderately strong), and $\geq 0.8$ (very strong). $\mathrm{P}<0.05$ was considered statistically significant.

\section{RESULTS}

The mean age of the study participants was $71.32 \pm 6.33$ years. Their demographic information, marital status, educational level, the information on chronic diseases, vision and sleep problems are presented in Table I. Notably, $79 \%$ of the individuals had a chronic disease. While $58 \%$ of the individuals had vision problems, $42 \%$ did not have any. While $37 \%$ of the participants stated that they had sleep problems, $63 \%$ stated that they did not have any (Table I). The individuals' chronic pain distribution and Standardized Mini-Mental Test, PASE, PSQI, and FSS test scores are presented in Table 2.

There was a weak positive correlation between the age of the individuals and the PSQI's Need Meds To Sleep (MEDS) sub-

\begin{tabular}{|c|c|}
\hline & $\mathrm{X} \pm \mathrm{SD}, \mathrm{n}(\%)$ \\
\hline Age, year & $71.32 \pm 6.33$ \\
\hline Height, cm & $160.65 \pm 26.59$ \\
\hline Body weight, kg & $72.26 \pm 11.68$ \\
\hline $\mathrm{BMl}, \mathrm{kg} / \mathrm{cm}^{2}$ & $26.53 \pm 4.46$ \\
\hline \multicolumn{2}{|l|}{ Gender ( $[\%])$} \\
\hline Female & $51(51.0)$ \\
\hline Male & $49(49.0)$ \\
\hline \multicolumn{2}{|l|}{ Marital status (n [\%]) } \\
\hline Married & $73(73.0)$ \\
\hline Widowed & $27(27.0)$ \\
\hline \multicolumn{2}{|c|}{ Educational status (n [\%]) } \\
\hline Primary school & $54(54.0)$ \\
\hline Secondary school & $9(9.0)$ \\
\hline High school & $14(14.0)$ \\
\hline University & $6(6.0)$ \\
\hline Uneducated & $17(17.0)$ \\
\hline \multicolumn{2}{|c|}{ The presence of chronic disease ( $\mathrm{n}[\%]$ ) } \\
\hline There is & $79(79.0)$ \\
\hline There is not & $21(21.0)$ \\
\hline \multicolumn{2}{|c|}{ Visual problem (n [\%]) } \\
\hline There is & $58(58.0)$ \\
\hline There is not & $42(42.0)$ \\
\hline \multicolumn{2}{|l|}{ Sleep problem (n [\%]) } \\
\hline There is & $37(37.0)$ \\
\hline There is not & $63(63.0)$ \\
\hline
\end{tabular}




\begin{tabular}{|c|c|c|}
\hline & $\mathrm{X} \pm \mathrm{SD}$ & $\begin{array}{c}\text { Med } \\
(\min -\max )\end{array}$ \\
\hline SMMT & $26.26 \pm 2.03$ & $26.26(24-30)$ \\
\hline Exercise Barrier Scale & $34.22 \pm 6.10$ & $34.22(19-47)$ \\
\hline Exercise Benefit Scale & $65.95 \pm 12.49$ & $65.95(33-107)$ \\
\hline $\begin{array}{l}\text { Exercise Barriers/Benefits Scale } \\
\text { total score }\end{array}$ & $100.57 \pm 13.96$ & $100.57(70-136)$ \\
\hline PASE leisure activity score & $33.38 \pm 37.39$ & $33.38(0-228.55)$ \\
\hline PASE housework activity score & $69.47 \pm 43.23$ & $69.47(0-146.00)$ \\
\hline PASE work activity score & $3.15 \pm 7.53$ & $3.15(0-21)$ \\
\hline PASE total score & $118.46 \pm 165.08$ & $118.46(0-163.64)$ \\
\hline Duration of Sleep (DURAT) & $0.20 \pm 0.56$ & $0.20(0-3)$ \\
\hline Sleep Disturbance (DISTB) & $1.63 \pm 0.63$ & $1.63(\mid-3)$ \\
\hline Sleep Latency (LATEN) & $1.34 \pm 0.84$ & $1.34(0-3)$ \\
\hline $\begin{array}{l}\text { Day Dysfunction Due To Sleepiness } \\
\text { (DAYDYS) }\end{array}$ & $0.93 \pm 0.92$ & $0.93(0-3)$ \\
\hline Sleep Efficiency (HSE) & $0.53 \pm 0.96$ & $0.53(0-3)$ \\
\hline Overall Sleep Quality (SLPQUAL) & $1.12 \pm 0.67$ & $1.12(0-3)$ \\
\hline Need Meds To Sleep (MEDS) & $0.48 \pm 1.04$ & $0.48(0-7)$ \\
\hline PSQI Total (PSQITOT) & $6.12 \pm 2.84$ & $6.12(2-13)$ \\
\hline FSS & $39.90 \pm 12.75$ & $39.90(9-63)$ \\
\hline
\end{tabular}

SMMT, Standardized Mini-Mental Test; PASE, Physical Activity Scale for the Elderly; FSS, Fatigue Severity Scale; PSQI, Pittsburgh Sleep Quality Index

scale and a very weak positive correlation between the PSQI total score and FSS. There was a weak positive correlation between the Exercise Barrier Scale and the PSQI's Day Dysfunction Due To Sleepiness (DAYDYS) and Overall Sleep Quality (SLPQUAL) subscale scores and a very weak positive correlation between the PSQI total score and FSS score. A very weak negative correlation was found between the Exercise Benefit Scale and the PASE total score. It was determined that the Exercise Barrier and Benefit Scale had a weak positive correlation with the DAYDYS subscale of the PSQI and a very weak positive correlation with the PSQI total score (Table 3).

A weak negative correlation was found between the PASE activity) score and the scores of the Duration of Sleep (DURAT) and SLPQUAL subscales of the PSQI, and a very weak negative correlation was found between the PASE (Leisure activity) $_{\text {score }}$ and the scores of the MEDS subscale, total PSQI, and FSS. A very weak negative correlation was detected between the PASE (Houseworkactivity) and the PSQI total scores. A very weak positive correlation was determined between the PASE (Work activity) and the DURAT scores, and a weak negative correlation was detected between sleep latency (LATEN) and FSS scores (Table 4).

\section{DISCUSSION}

Our study examined the relationship between exercise barriers/benefits and physical activity, sleep, and fatigue in older individuals. As a result, significant correlations were found between exercise barriers in older individuals and the PSQI's sleep quality and DAYDYS subparameters, the PSQI total score, and fatigue. Furthermore, significant correlations were detected between the PASE (Leisure activity) and sleep duration, sleep quality, $P S I_{(M E D S)} P S Q I_{(\text {Total) }}$ and fatigue severity, between the PASE ${ }_{(\text {Home }}$ activity) and PSQI ${ }_{(\text {Total) }}$ Score, and between PASE (Work activity) and sleep duration, sleep latency, and fatigue.

Exercise and physical activity have very significant benefits in older individuals and in all individuals (32). The importance of exercise for older individuals has been stated in many studies. Exercise positively affects bone structure, coordination, and mobility and thus decreases the risk of falls and fractures (33). Moreover, an important goal of exercise and physical activity in older individuals is to reduce the risk of falling. Falls in older individuals often cause injury, loss of functional independence, diseases associated with falls, and premature death (34). Alternatively, falling and the fear of falling are associated with increased psychological discomfort, limitation of activity and independence, and social isolation (35). Although significant evidence on the benefits of exercise for older individuals has been indicated, studies have reported that older individuals lead an increasingly passive life (36). In terms of physical activity, there are studies on motivational factors and exercise barriers in older individuals (37). In a study in which exercise barriers were explained, an individual's assessment of his or her health status as poor, pain, the lack of motivation, finding exercise boring, low belief in the individual's ability to exercise, exercise-associated pain, dizziness, shortness of breath, social concerns, and weather were indicated as the lack of information about the benefits of exercise (38). Burton et al. (39) reported that the barriers to older adults participating strength exercise training were poor health, risk of injury, pain, fatigue, lack of willpower, lack of positive attitude, low self-efficacy, lack of enjoyment, being too old, risk of heart attack, stroke or death, problems that interfere with daily living (work, social, etc.), nervousness or depression, lack of time, lack of knowledge, inconvenience, cost, low priority, lack of social support, lack of exercise facilities, geographic location, and lack of age-appropriate programs. Another study reported that the lack of time was a selected barrier by $27.4 \%$ of individuals aged $60-64$ years, $16.1 \%$ of those aged $65-69$ years, and $7.1 \%$ of those aged $\geq 70$ years. The lack of company (e.g. friends) and cognitive problems emerged as the most important barrier to physical activity among older adults (40). Sleep problems in older adults can cause fatigue, daytime sleepiness, and napping. Sleep problems also affect general functioning and activities of daily living and are associated with an increase in functional impairments, poorer quality of life, and cognitive and mental issues (4I). Therefore, we believe that sleep problems can also be an exercise barrier in older individuals. It is crucial to identify and overcome exercise barriers to enable the transition of older individuals from a sedentary lifestyle to a more active lifestyle (42).

By preventing chronic diseases often through reducing the associated effects of age-related biological changes on health and well-being, regular physical activity and exercise increase the average life expectancy (43). Maintaining an active life physically and mentally, an adequate and balanced diet, avoiding smoking and alcohol use, regular sleep, and stress control are key to healthy aging. Maintaining a physically active life leads to developing and maintaining physical fitness and supporting mental activities and reduces the risk of chronic diseases in 


\begin{tabular}{|c|c|c|c|c|c|}
\hline & & Years & $\begin{array}{c}\text { Exercise } \\
\text { Barrier Scale }\end{array}$ & $\begin{array}{c}\text { Exercise } \\
\text { Benefit Scale }\end{array}$ & $\begin{array}{l}\text { Exercise Barriers/ } \\
\text { Benefits Scale Total }\end{array}$ \\
\hline Duration of Sleep (DURAT) & $\begin{array}{l}r \\
p\end{array}$ & $\begin{array}{l}0.007 \\
0.943\end{array}$ & $\begin{array}{l}-0.042 \\
0.679\end{array}$ & $\begin{array}{l}0.053 \\
0.603\end{array}$ & $\begin{array}{l}0.018 \\
0.856\end{array}$ \\
\hline Sleep Disturbance (DISTB) & $\begin{array}{l}\mathrm{r} \\
\mathrm{p}\end{array}$ & $\begin{array}{l}0.172 \\
0.088\end{array}$ & $\begin{array}{l}-0.013 \\
0.900\end{array}$ & $\begin{array}{r}-0.025 \\
0.801\end{array}$ & $\begin{array}{l}-0.006 \\
0.949\end{array}$ \\
\hline Latency & $\begin{array}{l}r \\
p\end{array}$ & $\begin{array}{l}0.134 \\
0.182\end{array}$ & $\begin{array}{l}-0.001 \\
0.993\end{array}$ & $\begin{array}{l}0.051 \\
0.618\end{array}$ & $\begin{array}{l}0.047 \\
0.641\end{array}$ \\
\hline Day Dysfunction Due To Sleepiness (DAYDYS) & $\begin{array}{l}r \\
p\end{array}$ & $\begin{array}{l}0.130 \\
0.198\end{array}$ & $\begin{array}{l}0.279^{* *} \\
0.005\end{array}$ & $\begin{array}{l}0.154 \\
0.127\end{array}$ & $\begin{array}{l}0.297 * * \\
0.003\end{array}$ \\
\hline Sleep Efficiency (HSE) & $\begin{array}{l}r \\
p\end{array}$ & $\begin{array}{l}0.018 \\
0.858\end{array}$ & $\begin{array}{l}-0.071 \\
0.482\end{array}$ & $\begin{array}{l}0.147 \\
0.146\end{array}$ & $\begin{array}{l}0.099 \\
0.328\end{array}$ \\
\hline PSQI total (PSQITOT) & $\begin{array}{l}\mathrm{r} \\
\mathrm{p}\end{array}$ & $\begin{array}{l}0.198^{*} \\
0.049\end{array}$ & $\begin{array}{l}0.207^{*} \\
0.039\end{array}$ & $\begin{array}{l}0.127 \\
0.207\end{array}$ & $\begin{array}{l}0.211^{*} \\
0.035\end{array}$ \\
\hline \multicolumn{6}{|l|}{ PASE } \\
\hline PASE leisure activity score & $\begin{array}{l}\mathrm{r} \\
\mathrm{p}\end{array}$ & $\begin{array}{c}-0.038 \\
0.704\end{array}$ & $\begin{array}{l}0.089 \\
0.381\end{array}$ & $\begin{array}{l}-0.183 \\
0.068\end{array}$ & $\begin{array}{l}-0.102 \\
0.314\end{array}$ \\
\hline PASE housework activity score & $\begin{array}{l}r \\
p\end{array}$ & $\begin{array}{l}-0.190 \\
0.058\end{array}$ & $\begin{array}{l}-0.131 \\
0.193\end{array}$ & $\begin{array}{l}-0.017 \\
0.864\end{array}$ & $\begin{array}{l}-0.047 \\
0.642\end{array}$ \\
\hline PASE work activity score & $\begin{array}{l}r \\
p\end{array}$ & $\begin{array}{l}-0.132 \\
0.189\end{array}$ & $\begin{array}{l}0.054 \\
0.594\end{array}$ & $\begin{array}{l}0.022 \\
0.828\end{array}$ & $\begin{array}{l}0.085 \\
0.402\end{array}$ \\
\hline
\end{tabular}

older individuals (44). Sleep is one of the essential components of health-related quality of life (45). Increasing physical, social, psychological, and environmental changes with aging can lead to frequent sleep problems (46). Sleep quality is critical to maintain the homeostasis of the human body, which has been reported to be effective in the regulation of body temperature, metabolism, and immunity and the development, maturation, and plasticity of the brain, memory formation, and integration (47). It is believed that the need for sleep does not change with age, but sleep ability, as required, decreases mainly because of other factors such as physical or psychiatric diseases, excessive medication use, progression in the endogenous circadian rhythm, and age (48). Inadequate sleep quality in older individuals may result in decreased physical functionality, memory problems, increased risk of falls, and increased early mortality rates (48). Although there are very few studies, the relationship between sleep and physical function has been examined. Results indicate that sleep complaints and sleep disturbances are associated with functional independence (49). Furthermore, sleep quality is emphasized to be low in sedentary older individuals who have functional limitations (50). In the literature, physical activity in older individuals for at least 20-30 minutes per week was stated to positively affect sleep quality and general health (5I). In the study conducted on 2825 older individuals to evaluate sleep problems, Stenholm et al. (52) demonstrated that they were closely related to fatigue and physical functionality and that the evaluation of these factors in older individuals was important to identify individuals who had the risk of mobility dependence.

When the literature is examined, no studies that indicate that sleep quality may be one of the exercise barriers in older individuals are found. In the literature, studies have shown that sleep quality in older individuals is associated with functional independence. Therefore, because we believe that sleep quality may also be an exercise barrier, we evaluated sleep quality in older individuals in our study. The study results showed that a significant correlation was found between exercise barriers and sleep quality, DAYDYS, and the PSQI total score. Based on these results, we believe that sleep and sleep quality are exercise barriers in older individuals. We believe that regular and high-quality sleep ensures that older individuals keep fit and encourages them to exercise. Furthermore, in this study, in accordance with the literature, a significant correlation was detected between the PASE (leisure activity) and sleep duration, sleep quality, PSQI (MEDS) ${ }^{\prime}$ and PSQI $\left.\right|_{\text {(Total) }}$ and a significant correlation was also 
TABLE 4. Correlation of physical activity with sleep and fatigue

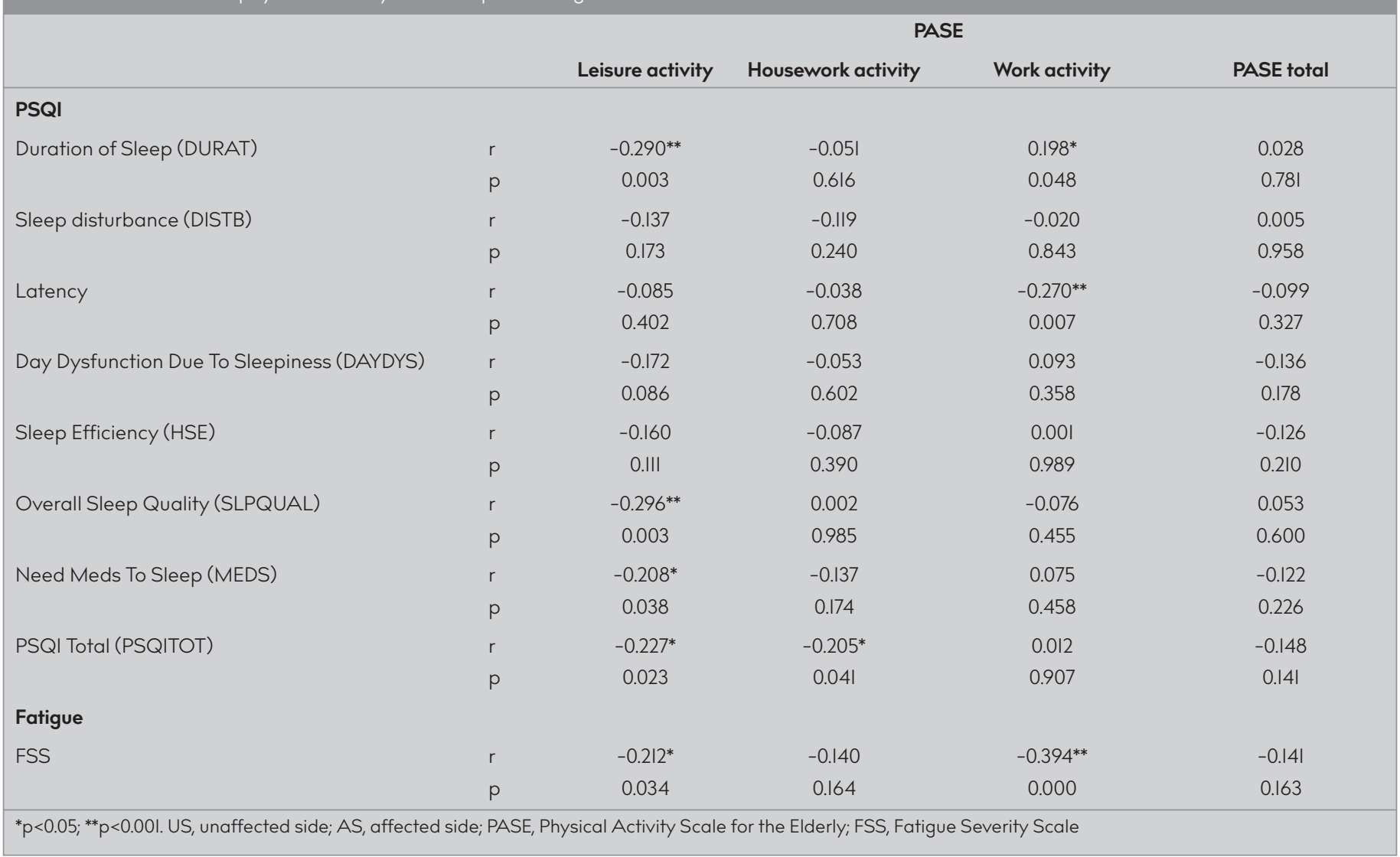

detected between the PASE (home activity) and PSQI (Total) $_{\text {score and }}$ between the PASE (work activity) and sleep duration and sleep latency. Physical activity in older individuals has been proven to be critical in terms of physical, mental, and psychological aspects (32). With this study, we believe that older individuals should be encouraged to do physical activity to improve their sleep duration and sleep quality and that their physical activity should be increased.

Fatigue is a condition that is felt at moderate and severe degrees during the aging process and is more common compared with adult individuals (53). In a study by Larsen et al. (54) who monitored fatigue in daily living activities, they evaluated older individuals in the 5th, 10 th, and 15 th years and noted that fatigue levels increased 9-fold in the 5th year and 2-fold in the I0th and I5th years compared with the 5 th year. This situation was associated with increased functional disability in older individuals. Yu et al. (53) stated that fatigue occurring with daily living activities in older individuals who were followed up for 1.5 years caused mobility deficiency by 3-fold in older women and 2-fold in older individuals. They also found that the rate of chronic fatigue in older individuals was $47.9 \%$. They also emphasized that the most common cause of fatigue in older individuals was sleep disturbance and the lack of exercise.

In the literature, it has been reported that the prevalence of fatigue increases with age and it is higher in older female individuals than in male individuals, and this is the most common cause of activity limitation in older individuals (55). In our study, a positive correlation was also found between age and fatigue severity. Similar to the literature, this study found that fatigue severity increases with increasing age. The reason for observing fatigue at a rate of $27 \%$ to $50 \%$ in older individuals may be chronic diseases, pain, malnutrition, and psychosocial factors (56). Fatigue in older individuals affects pain and mobility, leading to an inability to perform daily living activities (57). However, the interrelationship of other factors in the aging process, such as inflammation, depression, sleep complaints, self-efficacy, fatigue, and physical function, is complex and has not been fully explained (58). In our study, a significant relationship was found between the fatigue levels of older individuals and exercise barriers, the PASE (Leisure activity)! and $\mathrm{PASE}_{\text {(Work activity). In accordance with }}$ these results, we believe that fatigue is an exercise barrier in older individuals and that fatigue level is a factor affecting their physical activities.

According to the results of our study, a significant correlation was found between exercise barriers and sleep quality, DAYDYS, PSQI total score, and fatigue. A significant correlation was

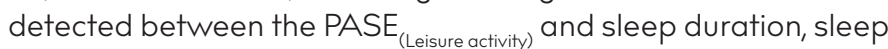
quality, PSQI $\mathrm{(MEDS}$ ) and PSQI (Total)' $^{\prime}$ and there was also a significant correlation between the PASE (Home activity) $_{\text {and } P S Q I_{(T o t a l)}}$ score

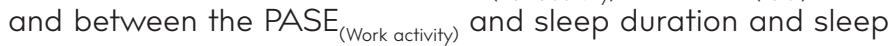
latency. Moreover, a significant correlation was found between fatigue levels and exercise barriers, the PASE (leisure activityy $_{\text {and }}$ $\mathrm{PASE}_{\text {(work activity) }}$ Considering these results, the evaluation of exercise barriers of older individuals in detail and the suggestion of appropriate physiotherapy and rehabilitation approaches will increase the functional independence of older individuals and improve their quality of life. According to the results of our study, 
conditions such as sleep quality and fatigue can be considered an exercise barrier. Regular exercise training planned for older individuals individually or as a group will improve sleep quality and provide improvement in the fatigue level. It is crucial to plan and implement in particular personal exercise and physical activity programs and lifestyle modifications, physiotherapy rehabilitation, and energy conservation techniques for sleep quality to maintain and improve the health of older individuals.

\section{Limitations of the Study}

Our work was done in a single nursing home. We believe the number of elderly individuals is insufficient. This study can be done by increasing the number of elderly individuals. In addition, the physical activities of older individuals can be evaluated with more objective tools.

Ethics Committee Approval: Ethics committee approval was received for this study from the ethics committee of Kırıkkale University, Non-interventional Research Ethics Committee, was found to be appropriate in terms of medical ethics (Meeting date: 06.02.2019; decision no: 2019.02.06).

Informed Consent: All individuals included in the study were informed in detail about the purpose and methodology of the study, and their consent for participation in the study was obtained.

Peer-review: Externally peer-reviewed.

Author contributions: Concept - M.S.; Design - M.S.; Supervision - M.S, S.A.A, C.S.D., T.Y.S.; Resource - S.B., A.A.K.; Materials - M.S.; Data Collection and/or Processing - M.A.O., K.U., B.Ö.; Analysis and/or Interpretation - S.A.A., T.Y.Ș.; Literature Search - S.B., A.A.K., Ö.V.; Writing - M.S.; Critical Reviews - M.S.

Conflict of Interest: Authors have no conflicts of interest to declare.

Financial Disclosure: The authors declared that this study has received no financial support.

\section{REFERENCES}

I. Cella D, Lai JS, Chang CH, Peterman A, Slavin M. Fatigue in cancer patients compared with fatigue in the general United States population. Cancer 2002; 94(2): 528-38. [Crossref]

2. Calkins E, Boult C, Wagner EH, Md M, Pacala JT. New ways to care for older people: Building systems based on evidence: Springer Publishing Company; 2004.

3. McDowell JA, Mion LC, Lydon TJ, Inouye SK. A nonpharmacologic sleep protocol for hospitalized older patients. J Am Geriatr Soc 1998; 46(6): 700-5. [Crossref]

4. Dimeo FC. Effects of exercise on cancer-related fatigue. Cancer 2001; 92(6 Suppl): 1689-93. [Crossref]

5. Germain P, Guell A, Marini JF. Muscle strength during bedrest with and without muscle exercise as a countermeasure. Eur $\mathrm{J}$ Appl Physiol Occup Physiol 1995; 7I(4): 342-8. [Crossref]

6. World Health Organization. WHO Global Strategy on Diet, Physical Activity and Health: Eastern Mediterranean Regional Consultation Meeting Report. World Health Organization, Cairo 2003. p.l-23.

7. Ludin AFM, Nor NAM, Omar S, Isa SNI, Ghoshal R, Kamaruddin MZA. Physical activity and health related quality of life among non-academic staff of a university. Malaysian J Med 20I5; I3(2). [Crossref]

8. Haskell WL, Lee IM, Pate RR, Powell KE, Blair SN, Franklin BA, et al. Physical activity and public health: updated recommendation for adults from the American College of Sports Medicine and the American Heart Association. Med Sci Sports Exerc 2007; 39(8): 1423-34. [Crossref]
9. Vuori I. Does physical activity enhance health? Patient Educ Couns 1998; 33(I Suppl): S95-I03. [Crossref]

10. Nakamura Y, Kikuchi H, Oka K, Ota A, Miyauchi T. Stage of change of exercise affects health-related quality of life. International J Sport Health 2006; 4: 67-73. [Crossref]

II. Shibata A, Oka K, Nakamura Y, Muraoka I. Recommended level of physical activity and health-related quality of life among Japanese adults. Health Qual Life Outcomes 2007; 5: 64. [Crossref]

12. Vuillemin A, Boini S, Bertrais S, Tessier S, Oppert JM, Hercberg S, et al. Leisure time physical activity and health-related quality of life. Prev Med 2005; 4I(2): 562-9. [Crossref]

13. Van Heuvelen MJ, Kempen Gl, Ormel J, Rispens P. Physical fitness related to age and physical activity in older persons. Med Sci Sports Exerc 1998; 30(3): 434-4I. [Crossref]

14. Hessert MJ, Gugliucci MR, Pierce HR. Functional fitness: maintaining or improving function for elders with chronic diseases. Fam Med 2005; 37(7): 472-6.

15. Milanovic Z, Pantelic S, Trajkovic N, Sporis G, Kostic R, James N. Age-related decrease in physical activity and functional fitness among elderly men and women. Clin Interv Aging 2013; 8: 549-56. [Crossref]

16. Palvanen $M$, Kannus P, Piirtola M, Niemi S, Parkkari J, Jarvinen M Effectiveness of the Chaos Falls Clinic in preventing falls and injuries of home-dwelling older adults: a randomised controlled trial. Injury 20l4; 45(I): 265-7I. [Crossref]

17. Sun F, Norman IJ, While AE. Physical activity in older people: a systematic review. BMC Public Health 2013; I3: 449. [Crossref]

18. Hallal PC, Andersen LB, Bull FC, Guthold R, Haskell W, Ekelund U. Global physical activity levels: surveillance progress, pitfalls, and prospects. Lancet 2012; 380(9838): 247-57. [Crossref]

19. Karan A. Yașllıkta egzersiz ve spor. Turk J Phys Med Rehab 2006; 52(Özel Ek A):53-6.

20. Belza B, Walwick J, Shiu-Thornton S, Schwartz S, Taylor M, LoGerfo J. Older adult perspectives on physical activity and exercise: voices from multiple cultures. Prev Chronic Dis 2004; I(4): A09.

21. Im EO, Lee B, Chee W, Stuifbergen A. Attitudes toward physical activity of white midlife women. J Obstet Gynecol Neonatal Nurs 20II; 40(3): 3/2-21. [Crossref]

22. Pender NJ, Lange. Health promotion in nursing Practice. 3rd. 1996; 251 .

23. Baltacı G. Irmak H, Kesici C, Eds. Fiziksel aktivite bilgi serisi. Klasmat Matbacilık. Ankara; 2008

24. Bárrios MJ, editor ILC-BR.Active Ageing: A Policy Framework in Response to the Longevity Revolution, International Longevity Centre Brazil, Rio de Janeiro, Brazil. Forum Sociológico Série Il; 2015: CESNOVA.

25. Ortabağ T, Ceylan S, Akyüz A, Bebiș H, Physical Education, Recreation. The validity and reliability of the exercise benefits/barriers scale for Turkish military nursing students. S Afr J Res Sprt Ph 20I0; 32(2): 55-70. [Crossref]

26. Sechrist KR, Walker SN, Pender NJ. Development and psychometric evaluation of the exercise benefits/barriers scale. Res Nurs Health 1987; 10(6): 357-65. [Crossref]

27. Ayvat E, Kilinc M, Kirdi N. The Turkish version of the Physical Activity Scale for the Elderly (PASE): its cultural adaptation, validation, and reliability. Turk J Med Sci 2017; 47(3): 908-15. [Crossref]

28. Buysse DJ, Reynolds CF, 3rd, Monk TH, Berman SR, Kupfer DJ. The Pittsburgh Sleep Quality Index: a new instrument for psychiatric practice and research. Psychiatry Res 1989; 28(2): 193-213. [Crossref]

29. Agargun MY, Kara H, Anlar O. Pittsburgh uyku kalitesi indeksinin gecerligi ve guvenirligi. Türk Psikiyatri Derg 1996; 7: 107-15.

30. Armutlu K, Korkmaz NC, Keser I, Sumbuloglu V, Akbiyik DI, Guney $Z$, et al. The validity and reliability of the Fatigue Severity Scale in Turkish multiple sclerosis patients. Int J Rehabil Res 2007; 30(I): 81-5. [Crossref]

31. Krupp LB, LaRocca NG, Muir-Nash J, Steinberg AD. The fatigue severity scale. Application to patients with multiple sclerosis and systemic lupus erythematosus. Arch Neurol 1989; 46(10): |121-3. [Crossref] 
32. McPhee JS, French DP, Jackson D, Nazroo J, Pendleton N, Degens H. Physical activity in older age: perspectives for healthy ageing and frailty. Biogerontology 2016; 17(3): 567-80. [Crossref]

33. Galloza J, Castillo B, Micheo W. Benefits of Exercise in the Older Population. Phys Med Rehabil Clin N Am 2017; 28(4): 659-69. [Crossref]

34. Bolding DJ, Corman E. Falls in the Geriatric Patient. Clin Geriatr Med 2019; 35(I): II5-26. [Crossref]

35. Bruce DG, Devine A, Prince RL. Recreational physical activity levels in healthy older women: the importance of fear of falling. J Am Geriatr Soc 2002; 50(1): 84-9. [Crossref]

36. Dacey ML, Newcomer AR. A client-centered counseling approach for motivating older adults toward physical activity. Top Geriat Rehabil 2005; 2I(3): 194-205. [Crossref]

37. de Groot GC, Fagerstrom L. Older adults' motivating factors and barriers to exercise to prevent falls. Scand J Occup Ther 20II; I8(2): 153-60. [Crossref]

38. Rasinaho M, Hirvensalo M, Leinonen R, Lintunen T, Rantanen T. Motives for and barriers to physical activity among older adults with mobility limitations. J Aging Phys Act 2007; 15(I): 90-I02. [Crossref]

39. Burton E, Farrier K, Lewin G, Pettigrew S, Hill AM, Airey P, et al. Motivators and Barriers for Older People Participating in Resistance Training: A Systematic Review. J Aging Phys Act 2017; 25(2): 311-24. [Crossref]

40. Booth ML, Bauman A, Owen N. Perceived barriers to physical activity among older Australians. J Aging Phys Act 2002; 10(3): 27I-80. [Crossref]

4l. Christie AD, Seery E, Kent JA. Physical activity, sleep quality, and self-reported fatigue across the adult lifespan. Exp Gerontol 2016; 77: 7-II. [Crossref]

42. Justine M, Azizan A, Hassan V, Salleh Z, Manaf H. Barriers to participation in physical activity and exercise among middle-aged and elderly individuals. Singapore Med J 2013; 54(10): 581-6. [Crossref]

43. Pedersen BK, Saltin B. Exercise as medicine - evidence for prescribing exercise as therapy in 26 different chronic diseases. Scand $J$ Med Sci Sports 2015; 25(Suppl 3): 1-72. [Crossref]

44. Harridge SD, Lazarus NR. Physical Activity, Aging, and Physiological Function. Physiology (Bethesda) 2017; 32(2): 152-61. [Crossref]

45. Hood B, Bruck D, Kennedy G. Determinants of sleep quality in the healthy aged: the role of physical, psychological, circadian and naturalistic light variables. Age Ageing 2004; 33(2): 159-65. [Crossref]

46. Malakouti SK, Foroughan M, Nojomi M, Ghalebandi MF, Zandi T. Sleep patterns, sleep disturbances and sleepiness in retired Iranian elders. Int J Geriatr Psychiatry 2009; 24(II): 120I-8. [Crossref]
47. Raven F, Van der Zee EA, Meerlo P, Havekes R. The role of sleep in regulating structural plasticity and synaptic strength: Implications for memory and cognitive function. Sleep Med Rev 2018; 39: 3-II. [Crossref]

48. Zdanys KF, Steffens DC. Sleep Disturbances in the Elderly. Psychiatr Clin North Am 2015; 38(4): 723-4l. [Crossref]

49. Park M, Buchman AS, Lim AS, Leurgans SE, Bennett DA. Sleep complaints and incident disability in a community-based cohort study of older persons. Am J Geriatr Psychiatry 2014; 22(7): 718-26. [Crossref]

50. Vaz Fragoso CA, Miller ME, Fielding RA, King AC, Kritchevsky SB, McDermott MM, et al. Sleep-Wake Disturbances in Sedentary Community-Dwelling Elderly Adults with Functional Limitations. J Am Geriatr Soc 2014; 62(6): 1064-72. [Crossref]

51. Whitehead BR, Blaxton JM. Daily Well-Being Benefits of Physical Activity in Older Adults: Does Time or Type Matter? Gerontologist 2017; 57(6): 1062-71. [Crossref]

52. Stenholm S, Kronholm E, Sainio P, Borodulin K, Era P, Fogelholm M, et al. Sleep-related factors and mobility in older men and women. J Gerontol A Biol Sci Med Sci 2010; 65(6): 649-57. [Crossref]

53. Yu DS, Lee DT, Man NW. Fatigue among older people: a review of the research literature. Int J Nurs Stud 2010; 47(2): 216-28. [Crossref]

54. Schultz-Larsen K, Avlund K. Tiredness in daily activities: a subjective measure for the identification of frailty among non-disabled community-living older adults. Arch Gerontol Geriatr 2007; 44(I): 83-93. [Crossref]

55. Moreh E, Jacobs JM, Stessman J. Fatigue, function, and mortality in older adults. J Gerontol A Biol Sci Med Sci 2010; 65(8): 887-95. [Crossref]

56. Goldman SE, Ancoli-Israel S, Boudreau R, Cauley JA, Hall M, Stone $\mathrm{KL}$, et al. Sleep problems and associated daytime fatigue in community-dwelling older individuals. J Gerontol A Biol Sci Med Sci 2008; 63(10): 1069-75. [Crossref]

57. Simonsick EM, Glynn NW, Jerome GJ, Shardell M, Schrack JA, Ferrucci L. Fatigued, but Not Frail: Perceived Fatigability as a Marker of Impending Decline in Mobility-Intact Older Adults. J Am Geriatr Soc 2016; 64(6): 1287-92. [Crossref]

58. Ramos V, Carraca EV, Paiva T, Baptista F. Sedentary Time, Physical Activity, Fitness, and Physical Function in Older Adults: What Best Predicts Sleep Quality? J Aging Phys Act 2019; 27(4): 538-44. [Crossref] 